\title{
Non ST-segment elevation myocardial infarction in patient with
} essential thrombocythemia

\author{
Emin Alioglu*1, Nurullah Tuzun1, Fahri Sahin'², Buket Kosova3, \\ Serkan Saygi ${ }^{4}$, Istemihan Tengiz ${ }^{1}$, Ugur Turk ${ }^{1}$, Nazan Ozsan ${ }^{5}$ and \\ Ertugrul Ercan ${ }^{6}$
}

\begin{abstract}
Address: ${ }^{1}$ Central Hospital, Department of Cardiology, Izmir, Turkey, ${ }^{2}$ Ege University School of Medicine, Department of Hematology, Izmir, Turkey, ${ }^{3}$ Ege University School of Medicine, Department of Medical Biology, Izmir, Turkey, ${ }^{4}$ Karsiyaka State Hospital, Department of Cardiology, Izmir, Turkey, ${ }^{5}$ Ege University School of Medicine, Department of Pathology, Izmire, Turkey and ${ }^{6}$ Canakkale Onsekiz Mart University, Faculty of Medicine, Department of Cardiology, Canakkale, Turkey

Email: Emin Alioglu* - dreminalioglu@yahoo.com; Nurullah Tuzun -drnurullahtuzun@yahoo.com; Fahri Sahin - fahri.sahin@ege.edu.tr; Buket Kosova - buket.kosova@ege.edu.tr; Serkan Saygi - serkansaygi@gmail.com; Istemihan Tengiz - dritengiz@yahoo.com; Ugur Turk -droturk@yahoo.com; Nazan Ozsan - nazan.ozsan@ege.edu.tr; Ertugrul Ercan - ertugrulercan@yahoo.com

* Corresponding author
\end{abstract}

Published: 20 February 2009

Thrombosis Journal 2009, 7:1 doi:10.1186/1477-9560-7-1
Received: 29 July 2008

Accepted: 20 February 2009

This article is available from: http://www.thrombosisjournal.com/content/7/I/I

(c) 2009 Alioglu et al; licensee BioMed Central Ltd.

This is an Open Access article distributed under the terms of the Creative Commons Attribution License (http://creativecommons.org/licenses/by/2.0), which permits unrestricted use, distribution, and reproduction in any medium, provided the original work is properly cited.

\begin{abstract}
A 68-year-old woman presented with acute chest pain and a greatly increased platelet count. Cardiac catheterization revealed subtotal occlusion and a thrombus-like filling defect in the right coronary artery. The patient was successfully treated with intravenous tirofiban. Essential thrombocythemia was diagnosed based on bone marrow findings, clinical presentation and laboratory analysis. The relationship between intracoronary thrombus and essential thrombocythemia is discussed.
\end{abstract}

\section{Introduction}

Essential thrombocythemia (ET) is a clonal disorder of unknown etiology involving a multipotent hematopoietic progenitor cell and is manifested clinically by the overproduction of platelets in the absence of a definable cause [1]. In 2008, the World Health Organization accepted the presence of the JAK2V617F mutation as a new diagnostic criterion for myeloproliferative neoplasms (MPNs) like polycythemia vera (PV), essential thrombocythemia (ET) and primary myelofibrosis (PMF) [2]. Platelets in this disorder also tend to be dysfunctional, in addition to being elevated in number [3]. The disease is associated with an elevated risk of thrombosis, hemorrhage, and vasomotor symptoms. Thrombotic events are not common but are usually deep venous thrombosis and pulmonary emboli
$[4,5]$. Coronary artery involvement is uncommon. We present a case of coronary thrombus involving the right coronary artery in a patient with ET.

\section{Case presentation}

A 68-year-old woman was admitted to our institution because of severe and sudden-onset chest pain. She underwent coronary angiography a year before which revealed a normal right coronary artery (RCA) with nonsignificant atherosclerotic lesions involving the other remaining coronary arteries. Her past medical history was significant for high platelet counts with a nonrevealing workup for myeloproliferative disease, and diabetes which was controlled medically. The patient's blood pressure on presentation was $135 / 70 \mathrm{mmHg}$ with a heart rate of 70 beats/minute. 
Physical examination revealed splenomegaly without any other significant pathological findings. Electrocardiography showed regular sinus rhythm with ST segment depression in the inferior derivations. The patient was diagnosed as having acute coronary syndrome (ACS). She was transported immediately to the catheterization laboratory. Coronary angiography, performed via the right femoral artery, showed subtotal occlusion and thrombus-like filling defect in the mid portion of the RCA (Figure 1). The left circumflex (LCx) and the left anterior descending artery (LAD) exhibited only mild irregularities without significant stenosis (Figure 2). Percutaneous coronary intervention was not performed. The patient was transferred to the coronary care unit where continuous infusion of tirofiban $(0.4 \mathrm{mcg} / \mathrm{kg} / \mathrm{min}$ bolus $)$ over 30 minutes followed by $0.25 \mathrm{mcg} / \mathrm{kg} / \mathrm{min}$ for 24 hours, heparin (1000 U/hours), and the oral combination of clopidogrel (75 mg/d before $300 \mathrm{mg}$ bolus), plus aspirin (100 mg/ day) was re-instituted. We kept the activated clotting time between 250 and $300 \mathrm{~s}$ during the infusion of heparin and tirofiban. A control coronary angiogram obtained three days later showed total dissolution of the coronary thrombus and normal clearance of the culprit vessel and TIMIIII flow was seen (Figure 3). Also, there was no distal embolization. Laboratory analysis showed leukocytosis (WBC: $17300 / \mathrm{mm}^{3}$ ) and thrombocytosis (platelet count:1.243.000/ $\mathrm{mm}^{3}$ ). Bone marrow aspirate revealed myeloid and megakaryocytic hyperplasia with mild degree fibrosis (Figure 4). Bone marrow biopsy of the patient was consistent with typical myeloproliferative disease and aspiration samples were sent to the Molecular Biology Laboratories of the Medical Biology Department,

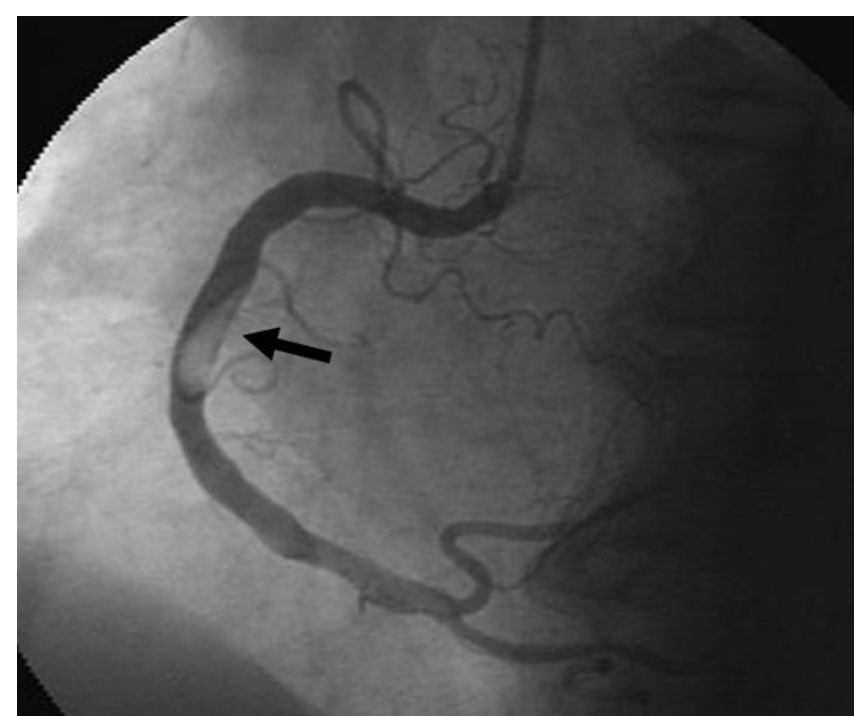

Figure I

Coronary angiography revealing thrombus-like filling defect in the mid portion of RCA.

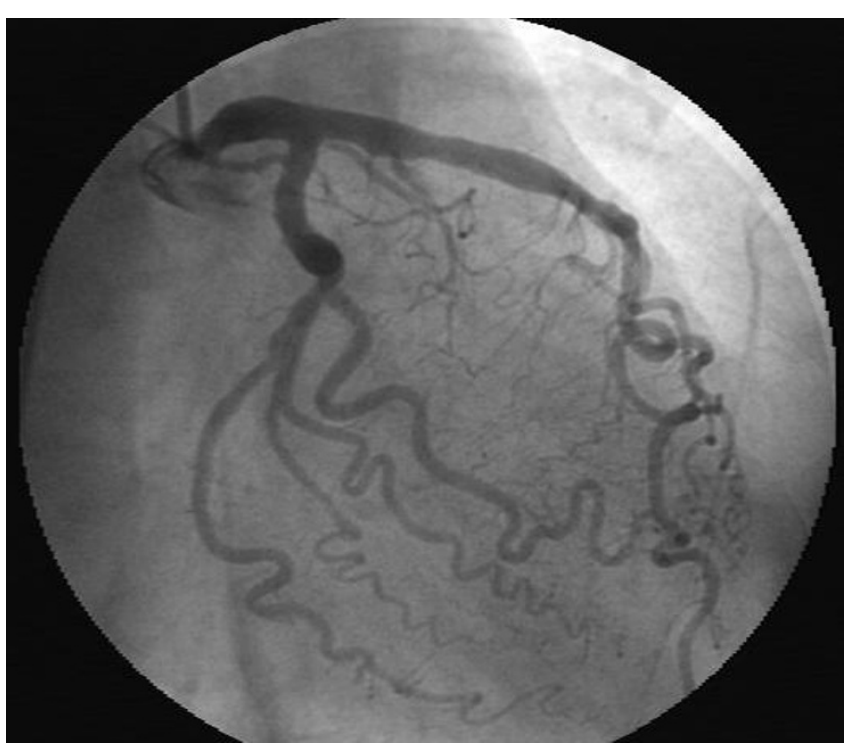

Figure 2

Left coronary angiography revealed no significant stenosis.

Ege University. Genomic DNA was extracted from peripheral blood leukocytes by using the High Pure PCR Template Preparation Kit (Roche Applied Science, Mannheim, Germany) and stored at $-20^{\circ} \mathrm{C}$ until use. Gene polymorphism and mutation analysis was either carried out by commercial available kits (LightCycler Factor V Leiden Mutation Detection Kit, and LightCycler Prothrombin (G20210A) Mutation Detection Kit, Roche Applied Science, Mannheim, Germany; LightMix Kit JAK2V617F

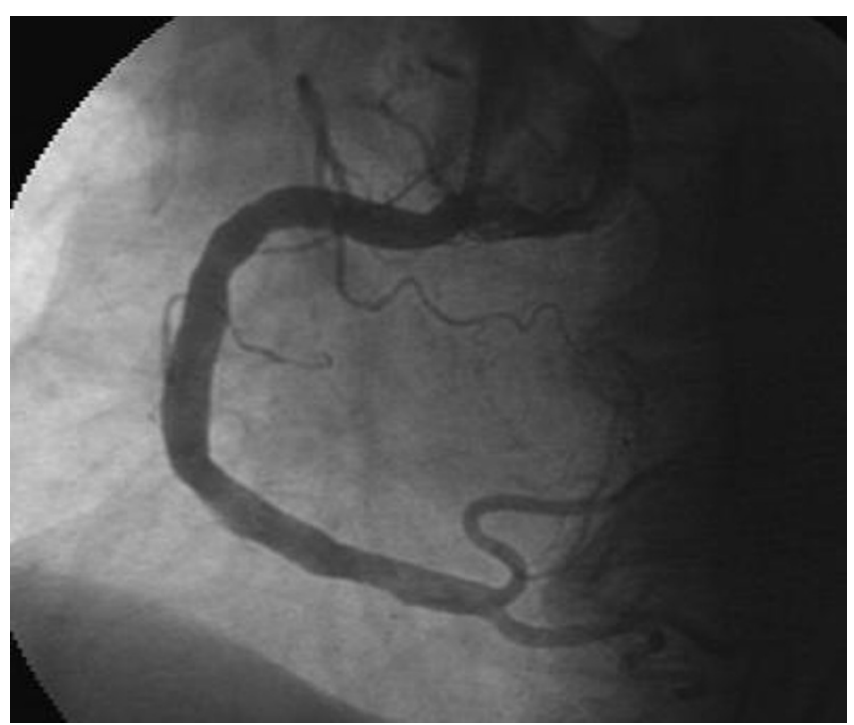

Figure 3

Coronary angiography revealing RCA free of thrombus. 


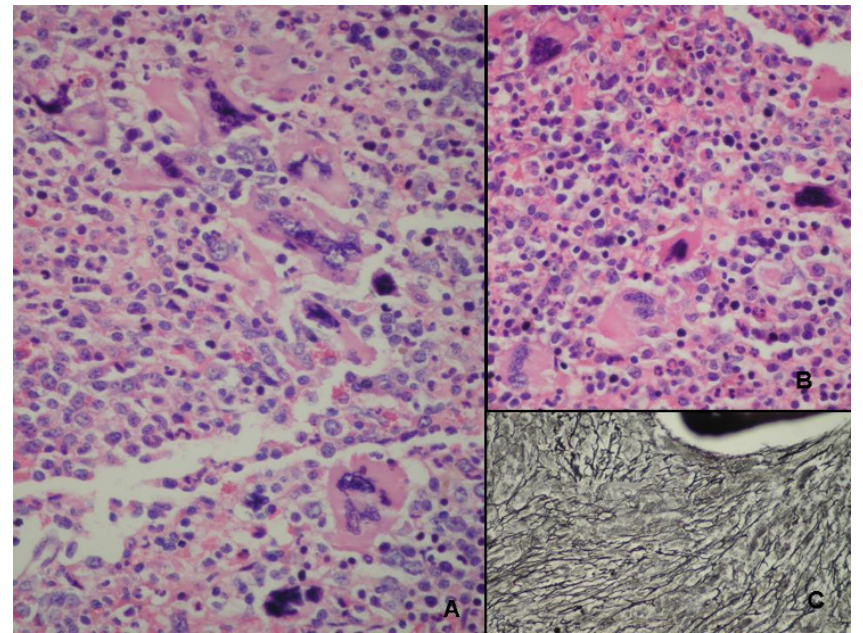

Figure 4

Bone marrow aspirate showed myeloid and megakaryocytic and megakaryocytic hyperplasia (A\&B) (Hematoxylin\&Eosin40) with mild degree fibrosisi (Reiculin stain $\times 20$ ).

genomic, LightMix for the detection of human MTHFR C677T, and LightMix for the detection of human Plasminogen Activator Inhibitor 4G/5G, TIB MOLBIOL, berlin, Germany) or in the case of the Factor XII C46T gene polymorphism by a protocol published from Tirodo, I. et al. [6]. All experiments were carried out on the LightCycler $^{\mathrm{TM}}$ Instrument ver.2.0 (Roche Applied Science; Mannheim, Germany).

Total RNA was isolated from bone marrow cells of the subject by using the High Pure RNA Isolation Kit (Roche Applied Science, Mannheim, Germany) and stored at $86^{\circ} \mathrm{C}$ until use. Quantitative bcr-abl analysis was performed with the LightCycler $t(9 ; 22)$ Quantification Kit on the LightCycler ${ }^{\mathrm{TM}}$ Instrument ver.2.0 (Roche Applied Science; Mannheim, Germany).

Bone marrow specimens were negative for the presence of the bcr/abl transcript. JAK2V617F mutation, Factor V Leiden (G 1691 A), Prothrombin gene (G 20210 A) mutations, MTHFR (C 677 T), Factor XIII (C 46 T), and PAI-1 $(4 \mathrm{G} / 5 \mathrm{G})$ genotype polymorphism analysis were performed to determine the potential hereditary risk factors for thrombophilia. PAI-1 4G/4G homozygote polymorphism and JAK2V617F heterozygote mutation were detected. Bone marrow findings, clinical presentation and laboratory analysis confirmed the diagnosis of essential thrombocythemia. Hydroxyurea was given to control the leukocyte and thrombocyte count.

\section{Discussion}

Intracoronary thrombus (ICT) may occur in ACS spontaneously, sometimes as a complication of interventional procedures and frequently superimposes on an existing atherosclerotic lesion [7]. However, an ICT or myocardial infarction with normal coronary arteries is a syndrome resulting from numerous conditions, but the exact cause in a majority of patients remains unknown. Possible mechanisms include embolism, vasospasm, nonatherosclerotic coronary diseases, hypercoagulable states, trauma, an imbalance between oxygen demand and supply, intense sympathetic stimulation, and endothelial dysfunction [8]. Because of RCA was determined as normal on recent angiogramme, the possible mechanism of thrombus in our case is considered due to hypercoagulablity that induced essential thrombocythemia.

Myeloproliferative disorders are a heterogeneous group of diseases characterized by excessive proliferation of cells originated from the myeloid lineage. Chronic myeloid leukemia, polycythemia vera, essential thrombocythemia and myelofibrosis are leading forms of the disorder. ET is a clonal disorder of a multipotent stem cell resulting in thrombocytosis, leukocytosis $[9,10]$. Patients with ET are thought to be at increased risk of thromboembolic events. Arterial ischemic complications may occur in these patients [10]. Elevated platelet count is regarded as risk factor, although the significance of these parameters has not been confirmed by clinical studies $[11,12]$.

At diagnosis, 5\% of ET patients show chromosomal abnormalities [13]. The most common cytogenetic abnormalities detected by conventional cytogenetic techniques are deletions in the long arms of chromosomes 20 and 13, duplication of 1q, and trisomies of chromosomes 8 and 9 [13]. Kralovics et al. [13] found loss of heterozygosity to be present in chromosome 9p, where JAK2 resides. JAK2 is a member of the Janus family of cytoplasmic non-receptor tyrosine kinases. A guanine-to-thymidine substitution, which results in a substitution of valine for phenylalanine at codon 617 of JAK2 (JAK2V617F), is responsible for the constitutively activity of this tyrosine kinase that activates signal transducer and activator of transcription (STAT), mitogen activated protein kinase (MAPK) and phosphotidylinositol 3-kinase (PI3K) signalling pathways, and transforms haematopoietic progenitor cells [14-16]. The discovery of JAK2V617F has led to the development of selective JAK2 inhibitors for the treatment of PV, ET and PMF $(6,16)$. Its exon 14 harbors JAK2V617F mutation, recently reported to be present in approximately $50 \%$ of ET. In addition, JAK2 exon 12 mutation in PV2, and a thrombopoietin receptor MPLW515L/K mutation in ET and myelofibrosis [17] are novel mutations that have been described in JAK2V617F mutation negative patients. In ET in particular, approximately $50 \%$ of the patients are 
JAK2 mutation negative and only a small fraction (less than 5\%) has MPL mutation. However, recent studies have showed that no significant differences for clinical complications except megakaryocyte counts between the patients with JAK2 V617F-positive and -negative [18].

Sarecka et al. reported the relationship between 5G allele of PAI-1 gene and the coronary artery disease. This data and the previously recorded data and Hindorff et al. reported that $4 \mathrm{G}$ allele was associated with a reduced risk of myocardial infarction and in the premenopausal women group $5 \mathrm{G}$ allele was correlated with a higher risk of infarct [19-21]. Böttiger et al. found no association between the $4 \mathrm{G} / 5 \mathrm{G}$ promoter polymorphism of the PAI-1 gene and angiographic restenosis or clinical outcome after coronary artery stenting in a large consecutive cohort of patients [22]. Our case had homozigous PAI-1 4G/4G and heterozygote JAK2V617F polymorphisms.

Douste-Blazy and associates reported that in cases of ET, pathophysiologic mechanisms of thrombus formation in different coronary arteries were 1) activation of thrombocytes as a result of endothelial damage, 2) extended arterial spasms and as a result formation of thrombus, 3) increased procoagulant activity of thrombocytes, 4) changes in glycoproteins on the surface of thrombocytes, and 5) possible deficiency of selective lipooxygenase [23]. ACS, developing in cases of ET, was not a result of atherosclerotic plaque rupture and was characterized by formation of the primary thrombus due to increased numbers of platelets, frequently in intramural arteries and rarely in epicardial arteries [24]. In these patients, coronary angiograms are frequently found to be normal [25]. No specific treatment of ACS, in patients with ET is reported. In the literature, only rare cases of application of conventional treatment or coronary angioplasty are found [26]. In this case, tirofiban, a GP IIb/IIIa receptor blocker, was preferably used, taking into account the pathophysiology of the disease.

Therefore, it may be thought that, in patients with ET, thrombolytic resistance treatment could develop in ACS generated by primary platelet rich thrombus, and blocking the GP IIb/IIIa receptors could break the continuing chain of aggregation and activation. Clinical improvement following tirofiban treatment, noticed without any complication was observed. Coronary angiograms support our concept of the use of GP IIb/IIIa receptors blockers in this case.

Identification and successful treatment of similar cases with tirofiban will help in further understanding of the pathophysiology of acute coronary syndromes in patients with ET.

\section{Competing interests}

The authors declare that they have no competing interests.

\section{Consent}

Written informed consent was obtained from the patient for publication of this case report and accompanying images. A copy of the written consent is available for review by the Editor-in-Chief of this journal.

\section{Authors' contributions}

EA carried out management of patient in coronary care unit and participated in second coronary angiography. NT collected material about similar cases. FS carried out the hematological tests. BK carried out the genetic examination. SS collected material about similar cases. IT performed first coronary angiography. UT performed second coronary angiography. NO participated in pathological examination of specimens obtained from bone marrow. EE participated in the sequence alignment. All authors read and approved the final manuscript.

\section{References}

I. Spivak JL: Polycythemia vera and other myeloproliferative diseases. In Harrison's Principles of Internal Medicine Volume I. 14th edition. Edited by: Fauci AS, Braunwald E, Isselbacher KJ, Wilson JD, Martin JB, Kasper DL, Hauser SL, Longo DL. The McGraw-Hill Companies, Inc., New York; 1998:683-684.

2. Tefferi A, Vardiman JW: Classification and diagnosis of myeloproliferative neoplasms: The $2008 \mathrm{WHO}$ criteria and pointof-care diagnostic algorithms. Leukemia 2008, 22: |4-22.

3. Cortelazzo S, Viero P, Finazzi G, D'Emilio A, Rodeghiero F, Barbui T: Incidence and risk factors for thrombotic complications in a historical cohort of 100 patients with essential thrombocythemia. J Clin Oncol 1990, 8:556-62.

4. Mitus AJ, Schafer Al: Thrombocytosis and thrombocythemia. Hematol Oncol Clin North Am 1990, 4: I57-77.

5. Silverstein MN: Primary or hemorrhagic thrombocythemia. Arch Intern Med 1968, I 22: 18-22.

6. Tirodo I, Fontcuberta J, Soria JM: Rapid detection of the 46C --> $T$ polymorphism in the factor $X I I$ gene, a novel genetic risk factor for thrombosis, by melting peak analysis using fluorescence hybridization probes. Genet Test 2003, 7:295-30I.

7. Zhou J, Chew M, Ravn HB, Falk E: Plaque pathology and coronary thrombosis in the pathogenesis of acute coronary syndromes. Scand J Clin Lab Invest (Suppl) 1999, 230:3-I I.

8. Tun $A$, Khan IA: Myocardial infarction with normal coronary arteries: the pathologic and clinical perspectives. Angiology 2001, 52:299-304.

9. Michiels JJ, Bernema Z, Van Bockstaele D, De Raeve H, Schroyens W: Current diagnostic criteria for the chronic myeloproliferative disorders (MPD) essential thrombocythemia (ET), polycythemia vera (PV) and chronic idiopathic myelofibrosis (CIMF). Pathol Biol (Paris) 2007, 55(2):92-104.

10. Sahin F, Saydam G: Essential thrombocythemia and cardiac disorders. J Card Res 2007, 6: I |6-122.

II. Wehmeier A, Daum I, Jamin H, Schneider W: Incidence and clinical risk factors for bleeding and thrombotic complications in myeloproliferative disorders. A retrospective analysis of $\mathbf{2 6 0}$ patients. Ann Hematol 1991, 63:101-106.

12. Gunes Y, Erbas C, Okuyan E, Babalik E, Gurmen T: Myocardial infarction with intracoronary thrombus induced by anabolic steroids. Anadolu Kardiyol Derg 2004, 4(4):357-8.

13. Kralovics R, Skoda RC: Molecular pathogenesis of Philadelphia chromosome negative myeloproliferative disorders. Blood Rev 2005, 19:1-13.

14. Levine RL, Wadleigh M, Cools J, Ebert BL, Wernig G, Huntly BJ, Boggon TJ, Wlodarska I, Clark JJ, Moore S, Adelsperger J, Koo S, Lee JC, Gabriel S, Mercher T, D'Andrea A, Fröhling S, Döhner K, Marynen P, 
Vandenberghe P, Mesa RA, Tefferi A, Griffin JD, Eck MJ, Sellers WR, Meyerson M, Golub TR, Lee SJ, Gilliland DG: Activating mutation in the tyrosine kinase JAK2 in polycythemia vera, essential thrombocythemia, and myeloid metaplasia with myelofibrosis. Cancer Cell 2005, 7:387-397.

15. Pardanani A, Hood J, Lasho T, Levine RL, Martin MB, Noronha G, Finke C, Mak CC, Mesa R, Zhu H, Soll R, Gilliland DG, Tefferi A: TGI01209, a small molecule JAK2-selective kinase inhibitor potently inhibits myeloproliferative disorder-associated JAK2V6I7F and MPLW5I5L/K mutations. Leukemia 2007, 21:1658-1668.

16. Dobrzanski P: CEP-70I Is a JAK2 inhibitor which attenuates JAK2/STAT5 signaling pathway and the proliferation of primary cells from patients with myeloproliferative disorders. Blood 2006, I08:. abst. 3594.

17. Pardanani AD, Levine RL, Lasho T, Pikman Y, Mesa RA, Wadleigh M, Steensma DP, Elliott MA, Wolanskyj AP, Hogan WJ, McClure RF, Litzow MR, Gilliland DG, Tefferi A: MPL5I 5 mutations in myeloproliferative and other myeloid disorders: a study of 1182 patients. Blood 2006, 108:3472-6.

18. Borze I, Mustjoki S, Juvonen E, Knuutila S: Haematologica. 2008, 93(5):787-8.

19. Hindorff LA, Schwartz SM, Siscovick DS, Psaty BM, Longstreth WT Jr, Reiner AP: The association of PAI-I promoter 4G/5G insertion/deletion polymorphism with myocardial infarction and stroke in young women. J Cardiovasc Risk 2002, 9:|3|-|37.

20. Yamada $Y$, Izawa $H$, Ichihara $S$, Takatsu F, Ishihara $H$, Hirayama $H$, Sone T, Tanaka M, Yokota M: Prediction of the risk of myocardial infarction from polymorphisms in candidate genes. $\mathrm{N}$ Engl J Med 2002, 347:1916-1923.

21. Sarecka B, Zak I, Krauze J: Synergistic effects of the polymorphisms in the PAI-I and IL-6 genes with smoking in determining their associated risk with coronary artery disease. Clin Biochem 2008 in press.

22. Böttiger C, Koch W, Lahn C, Mehilli J, von Beckerath N, Schömig A, Kastrati $A: 4 G / 5 G$ polymorphism of the plasminogen activator inhibitor-I gene and risk of restenosis after coronary artery stenting. Am Heart J 2003, I 46(5):855-6I.

23. Douste-Blazy P, Taudou MJ, Delay M, Pris J, Sie P, Ribaut L, Ribaut L, Galinier F, Bernadet P: Essential thrombocythaemia and recurrent myocardial infarction. Lancet 1984, 2:992.

24. Virmani R, Popovsky MA, Roberts WC: Thrombocytosis, coronary thrombosis and acute myocardial infarction. Am JMed 1979, 67:498.

25. Kaya H, Gundogdu M, Tekin SB, Akarsu E, Bozkurt E: Essential thrombocythemia and recurrent myocardial infarction. Clin Lab Haematol 2000, 22:161.

26. Esteves FA, Costa FA, Lima AA, Kajita LJ, Martinez Filho EE: Essential thrombocythemia and acute myocardial infarction treated with rescue coronary angioplasty. Arq Brasil Cardiol 1999, 73:97.
Publish with Bio Med Central and every scientist can read your work free of charge

"BioMed Central will be the most significant development for disseminating the results of biomedical research in our lifetime. "

Sir Paul Nurse, Cancer Research UK

Your research papers will be:

- available free of charge to the entire biomedical community

- peer reviewed and published immediately upon acceptance

- cited in PubMed and archived on PubMed Central

- yours - you keep the copyright
BioMedcentral 